\title{
Prevalence and factors associated with one-year mortality of infectious diseases among elderly emergency department patients in a middle-income country
}

Maythita Ittisanyakorn ${ }^{1,2}$, Sukkhum Ruchichanantakul ${ }^{1}$, Alissara Vanichkulbodee ${ }^{1}$ and Jiraporn Sri-on ${ }^{1 *}$ (D)

\begin{abstract}
Background: This study aimed to determine the prevalence of infectious diseases and risk factors for one-year mortality in elderly emergency department (ED) patients.

Methods: A retrospective cohort study of patients aged 65 and over who visited the ED of one urban teaching hospital in Bangkok, Thailand and who were diagnosed with infectious diseases between 1 January 2016 and 30 June 2016.

Results: There were 463 elderly patients who visited ED with infectious diseases, accounting for $14.5 \%(463 / 3,196)$ of all elderly patients' visits. The most common diseases diagnosed by emergency physicians (EPs) were pneumonia [151 (32.6\%) patients] followed by pyelonephritis [107 (23.1\%) patients] and intestinal infection [53 (11.4\%) patients]. Moreover, 286 (61.8\%) patients were admitted during the study period. The in-hospital mortality rate was $22.7 \% .181$ (39.1\%) patients died within 1 year. Our multivariate analysis showed that age 85 years and older [odds ratio $(O R)=1.89 ; 95 \%$ confidence interval (Cl): 1.36-2.63], Charlson Co-morbidity Index score $\geq 5(\mathrm{OR}=3.51 ; 95 \% \mathrm{Cl} 2.14-5.77)$, lactate $\geq 4 \mathrm{mmol} / \mathrm{I}(\mathrm{OR}=2.66$; 95\% Cl 1.32-5.38), quick Sequential Organ Failure Assessment (qSOFA) score $\geq 2$ (OR=5.46; 95\% Cl 2.94-10.12), and platelet count $<100,000$ cells $/ \mathrm{mm}^{3}(\mathrm{OR}=3.19 ; 95 \% \mathrm{Cl} 1.15-8.83$ ) were associated with 1-year mortality.

Conclusions: In one middle-income country, infectious diseases account for $14.5 \%$ of elderly ED patients. Almost twothirds of patients presenting to ED with infection are admitted to hospital. One-third of elderly ED patients with infection died within 1 year. Age $\geq 85$ years, Charlson Co-morbidity Index score $\geq 5$, lactate $\geq 4 \mathrm{mmol} / \mathrm{l}$, qSOFA score $\geq 2$, and platelet count $<100,000$ cells $/ \mathrm{mm}^{3}$ predicted 1-year mortality rate.
\end{abstract}

Keywords: Infectious diseases, Emergency department, Elderly patients, Mortality rate

\section{Background}

Infectious diseases (IDs) are some of the most common causes of death worldwide $[1,2]$. Overall the trend of infectious diseases in developed countries is a decline, such as in the US; infectious diseases accounted for 797: 100,000 population in 1900 and declined to $97: 100,000$ population in 1996 [3, 4]. In contrast, when focusing on elderly populations in 1990-2002, the rate of hospital admission for IDs increased to 13\% [5]. One epidemiological study of elderly emergency department (ED)

\footnotetext{
* Correspondence: Jiraporn.rew@gmail.com

${ }^{1}$ The Department of Emergency Medicine, Vajira Hospital, Navamindradhiraj University, Bangkok, Thailand

Full list of author information is available at the end of the article
}

patients with IDs showed a resulting hospital admission rate of 57.2\% [6]. Likewise, an Israeli study from 2011 found an increased rate of hospital admission among older patients to $14.2 \%$ and the most common disease was lower respiratory tract infection, accounting for $41 \%$. A study in the Netherlands found the oldest-old populations (age $\geq 85$ years) who were independent in activities of daily living (ADL) beacame less able in ADLs with a diagnosis of infectious disease [7]. One study in Canada which assessed the temporal trend of salmonella infection found the incidence of infection in seniors could increase by $16 \%$ by 2018 [8].

Accelerated population aging is now well-established in many middle-income countries leading to an increased 
number of older adults. Thailand, a middle-income country, has an aging population will account for one-third of its total population in 2040 [9-11]. IDs were the second most common causes of death for Thai people. The mortality rate was 41:100,000 population in 2009 [12]. Lower respiratory tract infection was the most common infection [12]. Most Thai research on IDs has focused on specific diseases and in-hospital admission may limit the importance of follow-up ED visits [12-14].

To address the gap, we conducted a study to determine the prevalence of infectious diseases and risk factors for one-year mortality in elderly ED patients in one middle-income country.

\section{Methods}

\section{Design and setting}

This was a retrospective cohort study. We reviewed data of all patients aged 65 and older who had a diagnosis related to infectious disease between 1 January 2016 and 30 June 2016 and received treatment at one ED of a university hospital in Bangkok, Thailand. Our hospital has approximately 50,000 ED visits per year and 18\% of them are aged over 65 years. Patients with infectious diseases were identified initially by searching the hospital's electronic database using International Classification of Diseases 10th (ICD-10). The ICD-10 code were defined in supplement 1.

Exclusion criteria were patients with unspecified diagnoses such as fever unspecified, diarrhea unspecified, Systemic Inflammatory Response Syndrome (SIRS), patients who transferred to other hospitals, patients triaged in ED as a non-urgent.

\section{Definitions}

Polypharmacy was defined as the number of patients' medications $\geq 5$.

Sepsis fast track at this hospital was defined as patients who had at least 2 from 3 points of Systemic Inflammatory Response Syndrome (SIRS) criteria at triage; nurses then activated fast track by notifying EPs. SIRS at triage was defined as 1 . body temperature $<36^{\circ} \mathrm{C}$ or $>38^{\circ} \mathrm{C}$; 2 . heart rate $>90$ beats $/ \mathrm{min}$; and 3. respiratory rate $(\mathrm{RR})>$ 20/min.

Quick Sequential Organ Failure Assessment (qSOFA) was defined as 1 . systolic blood pressure $(\mathrm{SBP}) \leq 100$ $\mathrm{mmHg} ; 2$. respiratory rate $\geq 22 / \mathrm{min}$; and 3 . glasgow coma scale $(\mathrm{GCS})<15$.

\section{Data collection process}

The data collection was done by a third-year emergency resident, medical students in their sixth year, and a registered nurse who had three years' practicing experience in ED. Data were extracted from electronic medical records (EMR), which included ED diagnosis, laboratory information system, and ICD-10 codes. For in-hospital patients, we extracted diagnostic data from summaries of the notes of resident doctors who were in charge of each ward. Our hospital has a policy that attending physicians recheck diagnoses.

\section{Research assistants training process}

Medical students and the registered nurse [research assistants (RAs)] were trained to collect data under supervision of the principle investigator (PI). This included three hours' training for data collection and identifying medical terms. RAs met the principle investigator once a month to clarify terms and data that were not clear. Furthermore, they could contact PI directly if they had problems with the terms or were unsure about data abstraction. The PI randomly selected $5 \%$ of medical records to test for interrater reliability between RAs for the subjective variables such as ED diagnosis. Kappa statistic was 0.84 .

The collected data consisted of age, gender, educations level, underlying diseases, number of medications, type of medications, Charlson co-morbidity index [15], activities of daily living (ADL) [16], modified Canadian triage level [17], activated sepsis fast track, quick Sequential Organ Failure Assessment (qSOFA) [18], vital signs, hemoculture, lactate, other specimen cultures such as sputum, urine, time to receive antibiotic, hospital admission rate, and in-hospital mortality rate. One-year mortality rate was determine by using database from Thailand Office of Central Civil Registration and hospital database, where available. All Thai people are registered to the system after their birth and given an identification number; after death the government also records this in the system.

Patients' informed consent was waived by the ethics committee of our hospital, since approval is not considered necessary for analyzing anonymous data for quality management. This study was approved by the hospital's institutional review board.

\section{Statistical analysis}

Quantitative values such as age, charlson comorbidity index score were presented using mean and standard deviation (SD) or median and interquartile range (IQR) where appropriate. The relationship between factors was determined by using student's t-test if the data were normally distributed or Mann Whitney $u$ test if the data were non-normally distributed. The calculation was statistically significant when $p$-value was less than 0.05. Qualitative values such as gender, hospital admission rate, and mortality rate were presented using percentages. Chi-square was used to test a relationship between factors, with $p$-value less than 0.05 being statistically significant. Multiple logistic regression analysis was used to determine risk factors associated with one-year mortality rate. The variables 
with a $p$-value $<0.1$ from univariate analysis were chosen for the final model and analyzed using backward selection methods. Hosmer-Lemeshow goodness of fit was used to determine the fit of the model. All statistical calculations found in this study were calculated by STATA software version 13.0.

\section{Results}

There were 3,467 elderly patients who visited ED between 1st January 2016 and 30th June 2016. 3,196 patients were triaged as urgent, emergency and resuscitation. There were 594 patients who had diagnosis of infectious diseases following ICD-10. This study excluded 67 patients with non-infectious diseases, 59 patients with unspecified infection and 5 patients were transferred to other hospitals. Finally, 463 elderly patients were diagnosed with infectious diseases, accounting for $14.5 \%(463 / 3,196)$ of all elderly ED patients' visits (Fig. 1).

Median age was 78 years (IQR 72-84). Most of the elderly patients arrived by family car [341 (73.7\%) patients]. 146 (31.5\%) patients had engagement in sepsis fast track. Median charlson co-morbidity index was 5 (IQR 4-6) (Table 1).

The most common diseases diagnosed by emergency physicians (EPs) were: pneumonia [151 (32.6\%) patients]; followed by pyelonephritis [107 (23.1\%) patients]; and intestinal infection [53 (11.4\%) patients]. Pneumonia [103 (36.0\%) patients] was the most common cause for hospital admission, followed by pyelonephritis [63 (23.4\%) patients] and intestinal infection [29 (10.1\%) patients] (Table 2).

$82 / 329$ (20.9\%) patients had a positive of hemoculture. $128 / 136(94.1 \%)$ had a positive sputum culture. Urine cultures were positive in 162/251 (64.5\%) patients, while pus cultures were positive in $9 / 9(100 \%)$ patients. Influenza screening was positive in $5 / 30(16.7 \%)$ patients.

Two-hundred and eighty-six (61.8\%) patients were admitted during the study period. Median hospital length of stay was 8 days (IQR $5-15$ ). The in-hospital mortality rate was $65(22.7 \%)$ patients. $181(39.1 \%)$ patients died within 1 year (Table 3).

Our multivariate analysis showed that age 85 years and older [odds ratio $(\mathrm{OR})=1.89 ; 95 \%$ confidence interval (CI): $1.36-2.63, p$-value $<0.001]$, charlson comorbidity index score $\geq 5(\mathrm{OR}=3.51 ; 95 \% \mathrm{CI} 2.14-5.77$, $p$-value $<0.001)$, lactate $\geq 4 \mathrm{mmol} / \mathrm{l} \quad(\mathrm{OR}=2.66 ; 95 \% \mathrm{CI}$ $1.32-5.38, p$-value <0.001), quick Sequential Organ Failure Assessment (qSOFA) score $\geq 2$ (OR $=5.46$; 95\% CI 2.94-10.12, $p$-value $=0.025)$, and platelet count < 100,000 cells $/ \mathrm{mm}^{3} \quad(\mathrm{OR}=3.19 ; 95 \%$ CI $1.15-8.83, p$ value $<0.001)$ were associated with 1 -year mortality (Table 4).

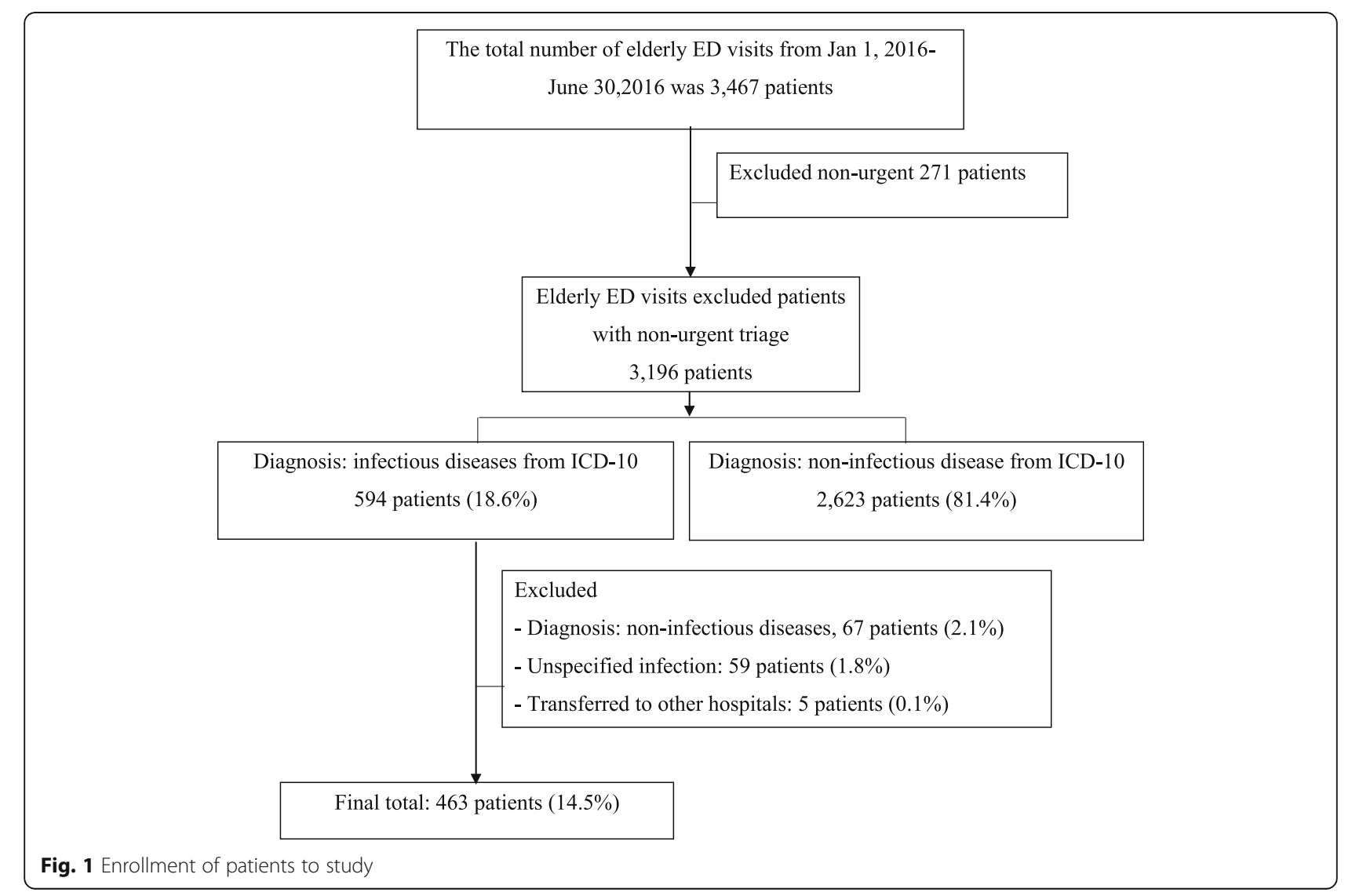


Table 1 Baseline characteristics, physical examination and investigation

\begin{tabular}{|c|c|c|}
\hline Variable $(n=463)$ & $\mathrm{N}$ & $(\%)$ \\
\hline Gender, male & 204 & $(44.1)$ \\
\hline Age, median (IQR) years & 78 & $72-84$ \\
\hline \multicolumn{3}{|l|}{ Patient's insurance } \\
\hline 30 Baht healthcare scheme ${ }^{a}$ & 226 & $(48.8)$ \\
\hline Social security & 9 & $(1.9)$ \\
\hline Government employee & 163 & $(35.2)$ \\
\hline Self-pay & 65 & $(14.0)$ \\
\hline \multicolumn{3}{|l|}{ Mode of arrival } \\
\hline Family car & 341 & (73.7) \\
\hline Ambulance & 68 & $(14.7)$ \\
\hline Others & 54 & (11.6) \\
\hline \multicolumn{3}{|l|}{ Triage level } \\
\hline Urgent & 253 & $(54.6)$ \\
\hline Emergency & 181 & (37.8) \\
\hline Resuscitation & 36 & $(7.8)$ \\
\hline Charlson comorbidity index, median (IQR) & 5 & $4-6$ \\
\hline Polypharmacy ( $\geq 5$ medications) & 175 & $(37.8)$ \\
\hline Sepsis fast track & 146 & (31.5) \\
\hline \multicolumn{3}{|l|}{ Temperature $\left({ }^{\circ} \mathrm{C}\right), n=451$} \\
\hline $36-38^{\circ} \mathrm{C}$ & 297 & (65.9) \\
\hline$<36$ or $>38^{\circ} \mathrm{C}$ & 154 & $(34.1)$ \\
\hline \multicolumn{3}{|l|}{ Heart rate (beat/min), $n=462$} \\
\hline$>90 / \mathrm{min}$ & 252 & $(54.3)$ \\
\hline$\leq 90 / \min$ & 211 & $(45.7)$ \\
\hline \multicolumn{3}{|l|}{ Respiratory rate (/min), $n=455$} \\
\hline$>20 / \mathrm{min}$ & 291 & (64.0) \\
\hline$\leq 20 / \min$ & 164 & $(36.0)$ \\
\hline \multicolumn{3}{|l|}{ Systolic blood pressure $(\mathrm{mmHg}), n=462$} \\
\hline$\leq 100$ & 53 & $(11.5)$ \\
\hline$>100$ & 409 & $(88.5)$ \\
\hline \multicolumn{3}{|l|}{ Oxygen saturation, $n=406$} \\
\hline$<90 \%$ & 54 & $(13.3)$ \\
\hline $90-93 \%$ & 51 & (12.6) \\
\hline$\geq 94 \%$ & 301 & $(74.1)$ \\
\hline \multicolumn{3}{|c|}{ Systemic inflammatory response syndrome [SIRS (points)] } \\
\hline $0-1$ & 169 & $(36.5)$ \\
\hline 2 & 132 & (28.5) \\
\hline 3 & 107 & (23.1) \\
\hline 4 & 55 & (11.9) \\
\hline \multicolumn{3}{|c|}{ Quick sequential organ failure assessment [qSOFA (points)] } \\
\hline $0-1$ & 373 & $(80.5)$ \\
\hline 2 & 75 & $(16.2)$ \\
\hline 3 & 15 & $(3.2)$ \\
\hline
\end{tabular}

Table 1 Baseline characteristics, physical examination and investigation (Continued)

\begin{tabular}{|c|c|c|}
\hline Variable $(n=463)$ & $\mathrm{N}$ & (\%) \\
\hline \multicolumn{3}{|c|}{ Hemoglobin (mg/dl), $n=450$} \\
\hline$<7$ & 22 & $(4.9)$ \\
\hline \multicolumn{3}{|c|}{ 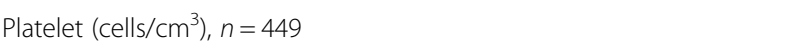 } \\
\hline$<100,000$ & 28 & $(6.2)$ \\
\hline \multicolumn{3}{|c|}{ Creatinine $(\mathrm{mg} / \mathrm{dl}), n=444$} \\
\hline$\geq 2$ & 78 & $(17.6)$ \\
\hline \multicolumn{3}{|c|}{ Creatinine clearance $[\mathrm{CrCl}(\mathrm{ml} / \mathrm{min})], n=445$} \\
\hline$>50$ & 254 & $(57.1)$ \\
\hline $10-50$ & 173 & $(38.9)$ \\
\hline$<10$ & 18 & $(4.0)$ \\
\hline \multicolumn{3}{|c|}{ Blood glucose $(\mathrm{mg} / \mathrm{dl}), n=345$} \\
\hline$\geq 180$ & 97 & $(28.1)$ \\
\hline \multicolumn{3}{|c|}{ Sodium (mmol/dl), $n=441$} \\
\hline$<135$ & 141 & $(32.0)$ \\
\hline $135-145$ & 283 & $(64.1)$ \\
\hline$>145$ & 17 & (3.9) \\
\hline \multicolumn{3}{|c|}{ Total bilirubin (mg/dl), $n=225$} \\
\hline$\geq 2$ & 26 & $(11.6)$ \\
\hline \multicolumn{3}{|c|}{ International normalized ratio (INR), $n=240$} \\
\hline$>1.5$ & 25 & $(10.4)$ \\
\hline \multicolumn{3}{|c|}{ Lactate $(\mathrm{mmol} / \mathrm{l}), n=361$} \\
\hline$\geq 2$ & 220 & $(60.9)$ \\
\hline$\geq 4$ & 59 & (16.3) \\
\hline
\end{tabular}

a 30 Baht healthcare scheme: Thailand has universal coverage healthcare which covers all medical expenses for the Thai populations

\section{Discussion}

The prevalence of infectious diseases among elderly ED patients in one middle-income country was $14.5 \%$. Three most common infections were pneumonia, pyelonephritis and intestinal infection. This finding was similar to that of Goto T, et al., who studied infectious disease-related ED visits of elderly adults in the United States, 2011-2012 [6]. They found the prevalence of infectious diseases in elderly ED patients was $13.5 \%$ and the two most common infections were lower respiratory tract infection (26.2\%) and urinary tract infection (25.3\%). In contrast, the rate of intestinal infection in our study was higher than Goto's study. The explanation may be due to the tropical climate that grows more organisms, such as vibrio cholerae [19]. The prevalence of elderly ED infection was less than a cohort study from The Netherlands, which found a $17 \%$ rate of infectious disease in patients aged equal to or more than 70 years [20].

Hospital admission rate in this study accounted for $61.8 \%$, similar to Goto T, et al. (57.1\%). On the other hand, the top three common causes of infection among 


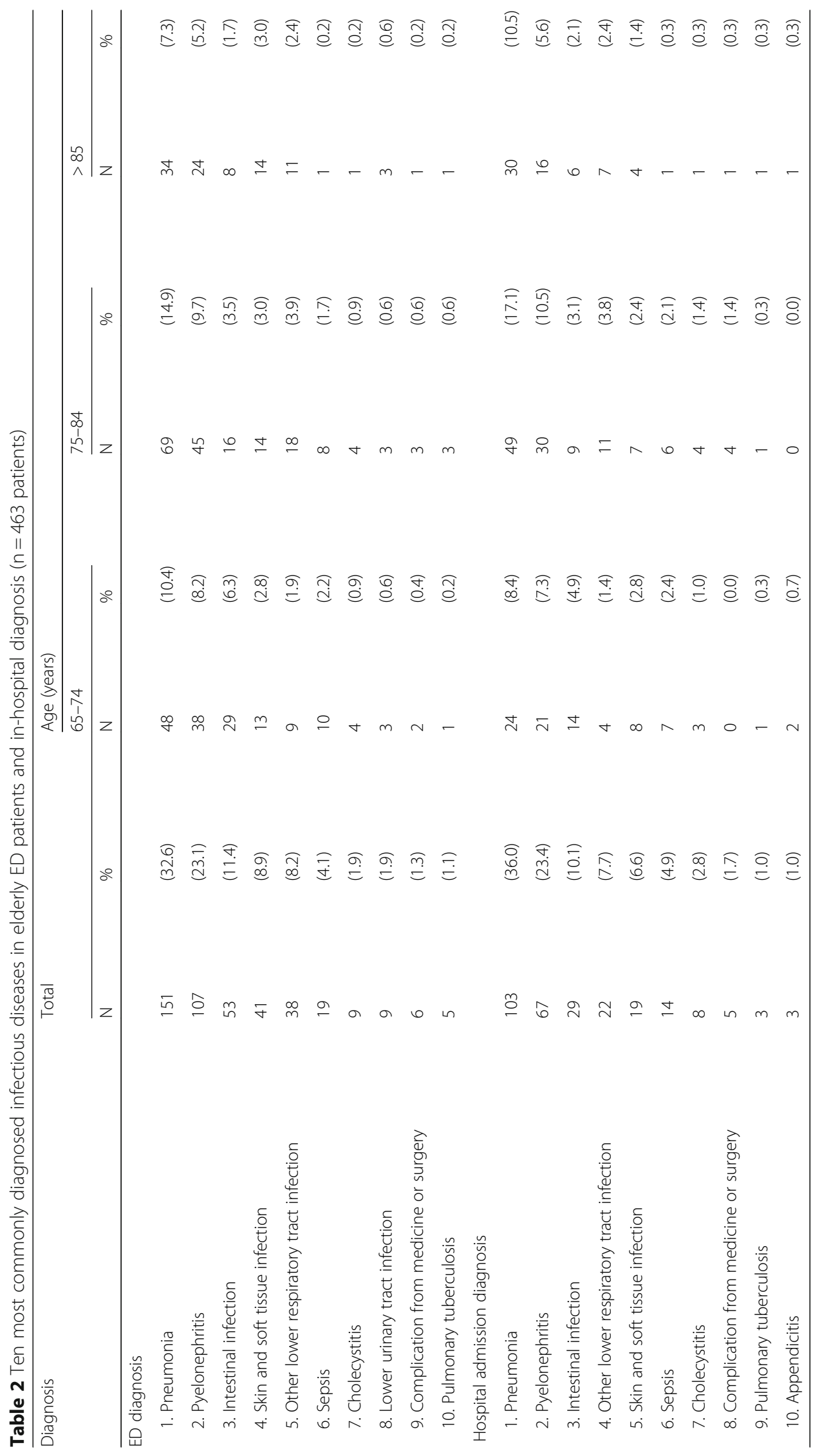


Table 3 Outcomes of infectious elderly ED patients

\begin{tabular}{ll}
\hline Variables & $\mathrm{N}(\%)$ \\
\hline ED disposition & $95(20.5)$ \\
Home & $65(14)$ \\
Other hospitals & $13(2.8)$ \\
Hospital admission & $286(61.8)$ \\
Death & $1(0.2)$ \\
Other & $3(0.6)$ \\
Hospital admission, $n=286$ patients & \\
Hospital length of stay, median (IQR) & $8(5-15)$ \\
Hospital disposition, $n=286$ & \\
$\quad$ Home & $219(76.6)$ \\
$\quad$ Refer to other hospital & $2(0.7)$ \\
$\quad$ Death & $65(22.7)$ \\
Mortality rate at 1 year & \\
Death & $181(39.1)$ \\
Causes of death & \\
Pneumonia & \\
Cancer & $46(26.4)$ \\
Urinary tract infection & $26(14.9)$ \\
Sepsis & \\
Unknown & \\
\end{tabular}

admitted patients in this study were pneumonia (36\%), pyelonephritis (23\%), and intestinal infection (10\%), whereas Goto's study found sepsis (32\%), lower respiratory tract infection (28\%), and urinary tract infection (17\%) were the top three causes of infection among admitted patients. Despite the utilization of the sepsis fast track system, 22\% of admission patients still died in this study, exactly comparable with Rebelo $M$, et al., who studied in-hospital mortality in elderly patients with bacteremia admitted to an internal medicine ward in Portugal and also found a rate of $22 \%$ [21]. This contrasts with Goto T, et al. whose study found only $4 \%$ died in-hospital. These findings may be a reflection on healthcare systems with the culture and environment differ.

Thirty-nine percent of infectious elderly ED patients died within one year.

Age $\geq 85$ were associated with one-year mortality rate. IDs among elderly patients are different from younger patients because of the immune response that reduces complement activity, decreases Naïve T-cells, as well as anatomic and physiological changes with aging such as decreased acid-base in gastric secretions, decreased estrogen in menopause, increased risk of urinary tract infection, and polypharmacy. Multiple comorbidities increase older adults' susceptibility to IDs [22-24]. Charlson co-morbidity index $>5$ predicted one-year mortality rate in our study, which was comparable with the results Murray SB, et al. [25] who found charlson co-morbidity index $>5$ had a $40 \%$ one-year mortality rate. Platelet count less than 100,000 cells $/ \mathrm{cm}^{3}$ also predicted one-year mortality rate, as noted in studies by Vincent JL, et al. [18] and Singer M, et al. [23]. qSOFA $\geq 2$ points was associated with one-year mortality rate in this study, which was comparable with Singer M, et al. whose study found qSOFA predicted mortality in Sepsis$3[26]$. Lactate concentration $\geq 4 \mathrm{mmol} / \mathrm{l}$ was associated with increased 1-year mortality rate, which was comparable to a study by Audren et al., which found lactate concentrations $>4 \mathrm{mmol} / \mathrm{L}$ had a specificity of $96 \%$ in predicting mortality in hospitalized non-hypotensive patients [27]. Other studies found higher serum lactate levels were associated with higher mortality rate [2830]. Clinically, hyperlactatemia ( $\geq 4 \mathrm{mmol} / \mathrm{l}$ ) can be considered a warning signal for organ dysfunction and a guide for medical intervention among elderly patients.

Although our hospital has a sepsis fast track, following the sepsis-3 recommendations, still one-fifth of older adults died within 1 year. Sepsis guidelines for elderly ED patients that focus on and oldest-old population with charlson co-morbidity index $>5$, lactate concentration $\geq 4 \mathrm{mmol} / \mathrm{l}$ and $\mathrm{qSOFA} \geq 2$ points may be beneficial.

\section{Limitations}

Due to the retrospective nature of this study, we could not know some information such as patients taking other medications besides those on the hospital record form and frailty informations. Our hospital did not performed a comprehensive geriatric assessment as a part of treatment on that time, the results may not generalized. We could not evaluate all causes of death as some of the data came from Thailand Office of Central Civil Registration, which records only the date of death. This study was a single-center study, the results may not be generalized. In multiple logistic regression analysis, we did not impute missing data because it may have widened CI if not missing completely at random (MCAR).

\section{Conclusion}

In one middle-income country, infectious diseases accounted for $14.5 \%$ in elderly ED patients. Pneumonia was the most common infection. Two thirds of these patients were admitted to hospital. One third of elderly ED patients died within 1 year. Age $\geq 85$ years, charlson comorbidity Index score $\geq 5$, lactate concentration $\geq 4$ $\mathrm{mmol} / \mathrm{l}$, qSOFA score $\geq 2$, and platelet count $<100,000$ cells $/ \mathrm{mm}^{3}$ predicted 1 -year mortality rate. Future research should focus on interventions to reduce mortality from infectious diseases in elderly ED patients. 


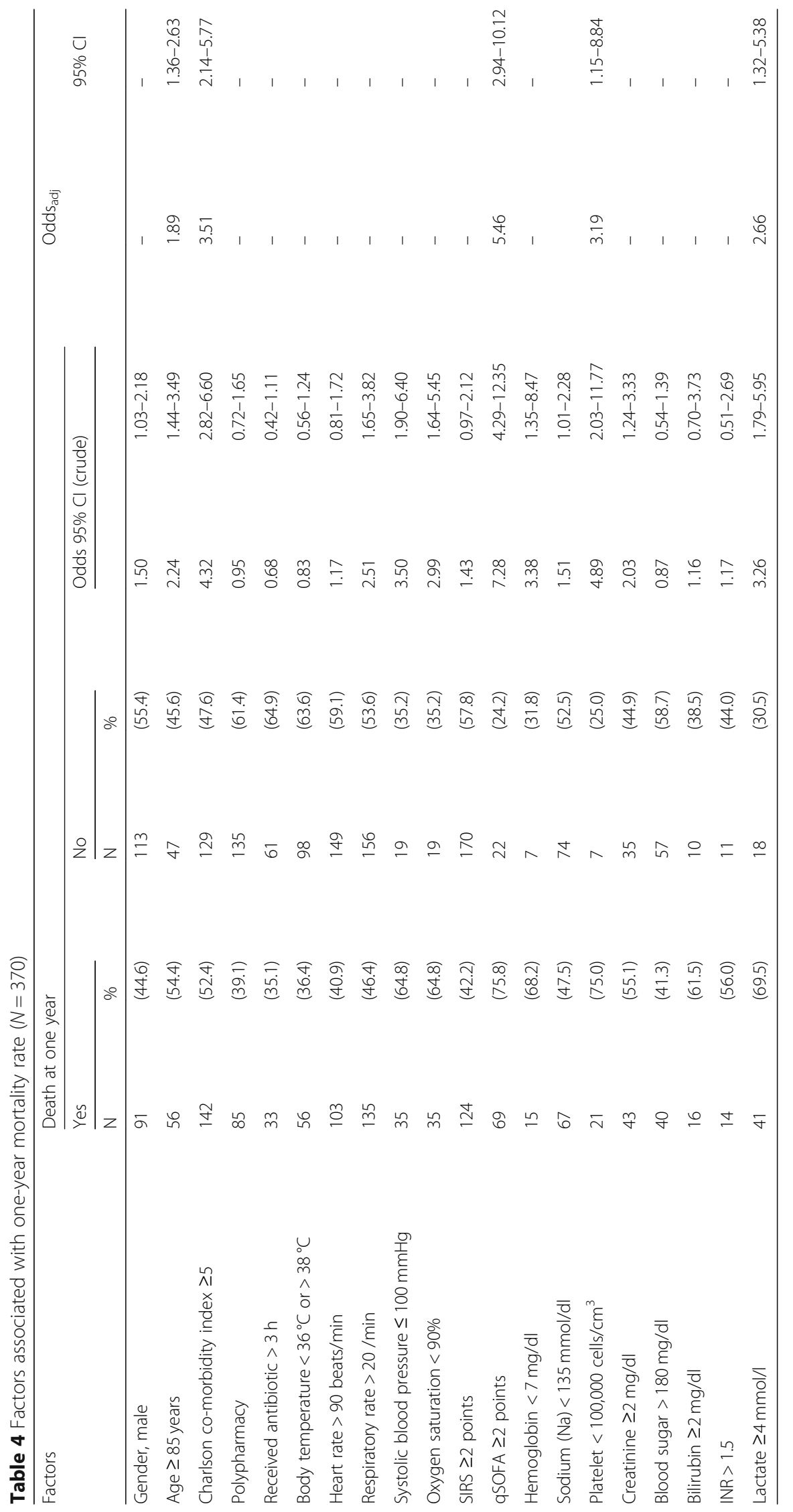




\section{Appendix 1}

ICD-10 for inclusion; code A00-A09, A15-A19, A20-A28, A30-A99, B00-B09, B15-B99, G00-G09, G73.4, G94.0, H03, H13, H19.2, H22.0, H32.0, H60, H75.0, H94.0, I00I02, I68.1, I98.0-0.1, J00-J06, J09-J18, J20-J22, J85-J86, K35-K37, K67, K75.0, K77.0, K81, L00-L08, L30.3, M00M03, M60.0, N08.0, N10-N12, N13.6, N16.0, N29.1, N39.0, N45, N70, N74, N77.0-0.1.

\begin{tabular}{|c|c|}
\hline ICD-10 codes & Definitions \\
\hline A00-A-09 & Intestinal infectious diseases \\
\hline A15-A19 & Tuberculosis \\
\hline A20-A28 & Certain zoonotic and bacterial diseases \\
\hline \multirow[t]{7}{*}{ A30-A99 } & A30-A40 Other bacterial diseases \\
\hline & A50-A64 Infections with a predominantly \\
\hline & $\begin{array}{l}\text { sexual mode of transmission A65-A69 } \\
\text { Other spirochaetal diseases }\end{array}$ \\
\hline & $\begin{array}{l}\text { A70-A74 Other diseases caused by } \\
\text { chlamydiae }\end{array}$ \\
\hline & A75-A79 Rickettsioses \\
\hline & $\begin{array}{l}\text { A80-A89 Viral infections of the central } \\
\text { nervous system }\end{array}$ \\
\hline & $\begin{array}{l}\text { A90-A99 Arthropod-borne viral fevers } \\
\text { and viral haemorrhagic fevers }\end{array}$ \\
\hline B00-B09 & $\begin{array}{l}\text { Viral infections characterized by skin } \\
\text { and mucous membrane lesions }\end{array}$ \\
\hline \multirow[t]{10}{*}{ B15-B99 } & B15-B 99Viral hepatitis \\
\hline & $\begin{array}{l}\text { B20-B24 Human immunodeficiency } \\
\text { virus [HIV] disease }\end{array}$ \\
\hline & B25-B34 Other viral diseases \\
\hline & B35-B49 Mycoses \\
\hline & B50-B64 Protozoal diseases \\
\hline & B65-B83 Helminthiases \\
\hline & $\begin{array}{l}\text { B85-B89 Pediculosis, acariasis and other } \\
\text { infestations }\end{array}$ \\
\hline & $\begin{array}{l}\text { B90-B94 Sequelae of infectious and } \\
\text { parasitic diseases }\end{array}$ \\
\hline & $\begin{array}{l}\text { B95-B98 Bacterial, viral and other } \\
\text { infectious agents }\end{array}$ \\
\hline & B99-B99 Other infectious diseases \\
\hline G00-G09 & $\begin{array}{l}\text { Inflammatory diseases of the central } \\
\text { nervous system }\end{array}$ \\
\hline G73.4 & $\begin{array}{l}\text { Myopathy in infectious and parasitic } \\
\text { diseases classified elsewhere }\end{array}$ \\
\hline G94.0 & $\begin{array}{l}\text { Hydrocephalus in infectious and parasitic } \\
\text { diseases classified elsewhere }\end{array}$ \\
\hline $\mathrm{H} 03$ & Disorders of eyelid, lacrimal system and orbit \\
\hline H13 & $\begin{array}{l}\text { Disorders of conjunctiva in diseases classified } \\
\text { elsewhere }\end{array}$ \\
\hline H19.2 & $\begin{array}{l}\text { Keratitis and keratoconjunctivitis in other } \\
\text { infectious and parasite diseases } \\
\text { classified elsewhere }\end{array}$ \\
\hline $\mathrm{H} 22.0$ & Iridocyclitis \\
\hline
\end{tabular}

Appendix 1 (Continued)

ICD-10 codes

$\mathrm{H} 32.0$

$\mathrm{H} 60$

H75.0

H94.0

$100-102$

168.1

198.0-0.1

J00-J06

J09-J18

$\mathrm{J} 20-\mathrm{J} 22$

J85-J86

K35-K37

K67

K 75.0

$\mathrm{K} 77.0$

K81

L00-L08

L30.3

M00-M03

M60.0

N08.0

$\mathrm{N} 10-\mathrm{N} 12$

N13.6

N 16.0

N29.1

N39.0

N45

N70

N74

N 77.0-0.1
Definitions

Chorioretinal inflammation in infectious and parasitic diseases classified elsewhere

Otitis media

Mastoiditis in infectious and parasitic diseases classified elsewhere

Acoustic neuritis in infectious and parasitic diseases classified elsewhere

Acute rheumatic fever

Cerebral arteritis in infectious and parasite diseases classified elsewhere

Cardiovascular syphilis

Acute upper respiratory infections

Influenza and pneumonia

Other acute lower respiratory infections

Suppurative and necrotic conditions of lower respiratory tract

Diseases of appendix

Disorder of peritoneum in infections disease classified elsewhere

Other inflammatory liver diseases

Liver disorders in infections and parasitic diseases classified elsewhere

Cholecystitis

Infections of the skin and subcutaneous tissue

Infective dermatitis

Infectious arthropathies

Myositis

Glomerular disorders in diseases classified elsewhere

Acute tubule-interstitial nephritis

Pyonephrosis

Renal tubulo-interstitial disorders in infectious and parasitic diseases classified elsewhere

Other disorders of kidney and ureter in infectious and parasitic diseases classified elsewhere

Urinary tract infection unspecified

Orchitis, epididymitis and epididymo-orchitis with abscess

Salpingitis and oophoritis

Female pelvic inflammatory disorders in diseases

classified elsewhere

Ulceration of vulva in infectious and parasitic diseases classified elsewhereVaginitis, vulvitis and vulvovaginitis in infectious and parasitic diseases classified elsewhere 


\section{Appendix 2}

Table 5 Outcomes of infectious elderly ED patients

\begin{tabular}{ll}
\hline Variables & $\mathrm{N}(\%)$ \\
\hline ED disposition & $95(20.5)$ \\
Home & $65(14)$ \\
ED observation & $13(2.8)$ \\
Other hospitals & $286(61.8)$ \\
Hospital admission & $1(0.2)$ \\
Death & $3(0.6)$ \\
Other & \\
Hospital admission, $\mathrm{n}=286$ patients & $8(5-15)$ \\
Hospital length of stay, median (IQR) & \\
Hospital disposition, $\mathrm{n}=286$ & $219(76.6)$ \\
$\quad$ Home & $2(0.7)$ \\
Refer to other hospital & $65(22.7)$ \\
Death & \\
Mortality rate at 1 year & $181(39.1)$ \\
Death & \\
Causes of death & $46(26.4)$ \\
Pneumonia & $26(14.9)$ \\
Cancer & $6(3.4)$ \\
Urinary tract infection & $20(11.4)$ \\
Sepsis & $763.7)$ \\
\hline
\end{tabular}

\section{Abbreviations}

ADL: Activity of daily living; Cl: Confidence interval; OR: odds ratio; ED: Emergency department; EPs: Emergency physicians; ICD-10: International Classification of Diseases 10th; IDs: Infectious diseases; IQR: Interquartile range; PI: Principle investigator; qSOFA: quick Sequential Organ Failure Assessment; RAs: Research assistants; RR: Respiratory rate; SBP: Systolic blood pressure; SD: Standard deviation; SIRS: Systemic Inflammatory Response Syndrome; $\mathrm{SpO}_{2}$ : Oxygen saturation

\section{Acknowledgements}

The authors would like to thank all patients for taking part in this study. We indepted to Mr. Jason Cullen for English editing. We acknowledge the support of nursing and medical staff of Vajira Hospital in Bangkok, Thailand.

\section{Competing of interests}

The authors declare that they have no competing interests.

\section{Authors' contributions}

$\mathrm{Ml}, \mathrm{AV}, \mathrm{SR}$, and JS conceived and design a study. JS, MI acquisition of the data. JS, MI analyses and interpretation of the data. JS, and MI drafted of the manuscript, JS, Ml, AV, SR, critical revision of the manuscript for important intellectual content and statistical expertise. All authors approved the final version of the manuscript to be published.

\section{Funding}

This study had fully supported by Vajira Research Foundation Grant for Research Development. The funders had no role in study design, data collection and analysis, decision to publish, or preparation of the manuscript.

\section{Availability of data and materials}

Data can be obtained from the corresponding author upon reasonable request.

\section{Ethics approval and consent to participate}

The study was approve by Ethic Review Board of Faculty of Medicine, Vajira Hospital, Navamindradhiraj University. The COA number is 16/2560. The Faculty of medicine, Vajira hospital, Navamindradhiraj University IRB permissions were required to access the raw data.

\section{Consent for publication}

Not applicable

\section{Author details}

${ }^{1}$ The Department of Emergency Medicine, Vajira Hospital, Navamindradhiraj University, Bangkok, Thailand. ${ }^{2}$ The Department of Emergency Medicine, Chaophya Abhaibhubejhr Hospital, Bangkok, Thailand.

Received: 13 February 2019 Accepted: 18 July 2019

Published online: 25 July 2019

\section{References}

1. Armstrong GL, Conn LA, Pinner RW. Trends in infectious disease mortality in the United States during the 20th century. JAMA. 1999;281(1):61-6.

2. Saliba W, Fediai A, Edelstein H, Markel A, Raz R. Trends in the burden of infectious disease hospitalizations among the elderly in the last decade. Eur J Intern Med. 2013:24(6):536-40.

3. Christensen KL, Holman RC, Steiner CA, Sejvar JJ, Stoll BJ, Schonberger LB. Infectious disease hospitalizations in the United States. Clin Infect Dis. 2009; 49(7):1025-35

4. Fry AM, Shay DK, Holman RC, Curns AT, Anderson LJ. Trends in hospitalizations for pneumonia among persons aged 65 years or older in the United States, 1988-2002. JAMA. 2005:294(21):2712-9.

5. Curns AT, Holman RC, Sejvar JJ, Owings MF, Schonberger LB. Infectious disease hospitalizations among older adults in the United States from 1990 through 2002. Arch Intern Med. 2005;165(21):2514-20.

6. Goto T, Yoshida K, Tsugawa Y, Camargo CA Jr, Hasegawa K. Infectious disease-related emergency department visits of elderly adults in the United States, 2011-2012. J Am Geriatr Soc. 2016;64(1):31-6.

7. Caljouw MA, Kruijdenberg SJ, de Craen AJ, Cools HJ, den Elzen WP, Gussekloo J. Clinically diagnosed infections predict disability in activities of daily living among the oldest-old in the general population: the Leiden 85plus study. Age and Aging. 2013;42(4):482-8.

8. Turgeon $\mathrm{P}, \mathrm{Ng} \vee$, Murray $\mathrm{R}$, Nesbitt $\mathrm{A}$. Forecasting the incidence of salmonellosis in seniors in Canada: a trend analysis and the potential impact of the deographic shift. PLoS One. 2018:27(11):e0208124.

9. Ousvapoom MP, Suthiart MA, Aryukasam MT, Senpong MS. Statistical Thailand 2013: Bureau of Policy and Strategy. Ministry of Public Health. 2013; https://www.m-society.go.th/article_attach/11378/15693.pdf. Accessed 4 Apr 2018.

10. Global health - Thailand. 2010. http://www.cdc.gov/globalhealth/countries/ thailand/. Accessed 12 Jan 2016.

11. Number of deaths by leading cause of death and sex, whole kingdom: 2007-2014. http://service.nso.go.th/nso/web/statseries/tables/00000_Whole_ Kingdom/deaths-50-57.xls. Accessed 14 Jan 2019.

12. Suchunya A, Margaret M, Jongkol L, Sonja JO, Kanitta B. Infectious disease mortality rates, Thailand, 1958-2009. Emerg Infect Dis. 2012;18(11):1794-801.

13. Whistler T, Sapchookul P, McCormick DW, Sangwichian O, Jorakate P, Jatapai $A$, et al. Epidemiology and antimicrobial resistance of invasive nontyphoidol salmonellosis in rural Thailand from 2006-2014. PLoS Negl Trop Dis. 2018;6(8):e0006718.

14. Hantrakun V, Somayaji R, Teparrukkul P, Boonsri C, Rudd K, Day NPJ, et al. Clinical epidemiologyand outcomes of community acquired infection and sepsis among hospitalized patients in a resource limited setting in Northeast Thailand: a prospective observational study (Ubon-sepsis). PLoS One. 2018;26(9):e0204509.

15. Charlson ME, Pompei $P$, Ales $K L$, Mackenzie CR. A new method of classifying prognostic comorbidity in longitudinal studies: development and validation. J Chronic Dis. 1987:40(5):373-83. 
16. Katz S, Ford AB, Moskowitz RW, Jackson BA, Jaffe MW. Studies of illness in the aged: the index of ADL: a standardized measure of biological and psychosocial function. JAMA. 1963;21(185):914-9.

17. Bullard MJ, Chan T, Brayman C, Warren D, Musgrave E, Unger B. Revisions to the Canadian emergency department triage and acuity scale (CTAS) guidelines. CJEM. 2014;16(6):485-9.

18. Vincent IL, de Mendonca A, Cantraine F, Mereno R, Takala J, Suter PM, et al. Use of the SOFA score to assess the incidence of organ dysfunction/failure in intensive care units: results of a multicenter, prospective study. Working group on "sepsis-related problems" of the European Society of Intensive Care Medicine. Crit Care Med. 1998;26(11):1793-800.

19. Tropical Diseases. http://www.astmh.org/education-resources/tropicalmedicine-q-a/major-tropical-diseases. Accessed 15 Dec 2017.

20. Schrijver EJ, Toppinga Q, de Vries OJ, Kramer MH, Nanayakkara PW. An observational cohort study on geriatric patient profile in an emergency department in the Netherlands. Neth J Med. 2013;71(6):324-30.

21. Rebelo M, Pereira B, Lima J, Decq-Mota J, Vieira JD, Costa JN. Predictors of in-hospital mortality in elderly patients with bacteraemia admitted to an internal medicine ward. Int Arch Med. 2011;4:33.

22. Ph K. Infection in the elderly. In: Jeffrey BH, Go J, Et M, S S, Ph K, A S, editors. Hazzaid's geriatric medicine and gerontology. 6 ed. New york: McGraw-Hill; 2009.

23. Birnbaumer DM. The Elder Patient. In: Marx JA, Hockberger RS, Walls RM, editors. Rosen's emergency medicine : concepts and clinical practice. 8 ed. Philadelphia: Saunders; 2013.

24. Castle SC. Clinical relevance of age-related immune dysfunction. Clin Infect Dis. 2000;31(2):578-85

25. Murray SB, Bates DW, Ngo L, Ufberg JW, Shapiro NI. Charlson index is associated with one-year mortality in emergency department patients with suspected infection. Acad Emerg Med. 2006;13(5):530-6.

26. Singer M, Deutschman CS, Shankar-Hari M, Annane D, Bauer M, Bellomo R, et al. The third international consensus definitions for sepsis and septic shock (sepsis-3). JAMA. 2016;315(8):801-10.

27. Aduen J, Bernstein WK, Khastgir T, Miller J, Kerzner R, Bhatiani A, et al. The use and clinical importance of a substrate-specific electrode for rapid determination of blood lactate concentrations. JAMA. 1994;272(21):1678-85. https://doi.org/10.1001/jama.1994.03520210062033.

28. Singer AJ, Taylor M, Domingo A, Ghazipura S, Khorasonchi A, Thode HC Jr, et al. Diagnostic characteristics of a clinical screening tool in combination with measuring bedside lactate level in emergency department patients with suspected sepsis. Acad Emerg Med. 2014;21(8):853-7. https://doi.org/1 $0.1111 /$ acem.12444.

29. Mikkelsen ME, Miltiades AN, Gaieski DF, Goyal M, Fuchs BD, Shah CV, et al. Serum lactate is associated with mortality in severe sepsis independent of organ failure and shock. Crit Care Med. 2009;37(5):1670-7.

30. Rivers EP, Kruse JA, Jacobsen G, Shah K, Loomba M, Otero R, et al. The influence of early hemodynamic optimization on biomarker patterns of severe sepsis and septic shock. Crit Care Med. 2007;35(9):2016-24. https:// doi.org/10.1097/01.CCM.0000281637.08984.6E.

\section{Publisher's Note}

Springer Nature remains neutral with regard to jurisdictional claims in published maps and institutional affiliations.

Ready to submit your research? Choose BMC and benefit from:

- fast, convenient online submission

- thorough peer review by experienced researchers in your field

- rapid publication on acceptance

- support for research data, including large and complex data types

- gold Open Access which fosters wider collaboration and increased citations

- maximum visibility for your research: over $100 \mathrm{M}$ website views per year

At $\mathrm{BMC}$, research is always in progress.

Learn more biomedcentral.com/submissions 